BMJ Open

Diabetes

Research

\& Care

\title{
Extended insulin boluses cannot control postprandial glycemia as well as a standard bolus in children and adults using insulin pump therapy
}

\author{
Prudence Lopez, ${ }^{1,2,3}$ Carmel Smart, ${ }^{1,2,3}$ Claire Morbey, ${ }^{4}$ Patrick McElduff, ${ }^{2}$ \\ Megan Paterson, ${ }^{1,2,3}$ Bruce R King ${ }^{1,2,3}$
}

To cite: Lopez P, Smart C Morbey $\mathrm{C}$, et al. Extended insulin boluses cannot control postprandial glycemia as well as a standard bolus in children and adults using insulin pump therapy. BMJ Open Diabetes Research and Care 2014;2:e000050. doi:10.1136/bmjdrc-2014000050

Received 31 July 2014 Revised 14 October 2014 Accepted 4 November 2014

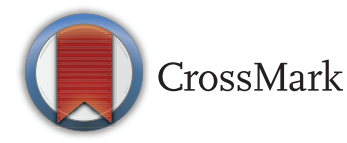

${ }^{1}$ Paediatric Endocrinology Department, John Hunter Children's Hospital,

Newcastle, New South Wales, Australia

${ }^{2}$ Faculty of Health and Medicine, The University of Newcastle, Newcastle, New South Wales, Australia ${ }^{3}$ Hunter Medical Research Institute, Newcastle, New South Wales, Australia

${ }^{4}$ AIM Diabetes Centre, Newcastle, New South Wales, Australia

\section{Correspondence to}

Dr Bruce King;

Bruce.King@hnehealth.nsw. gov.au

\section{ABSTRACT}

Introduction: Insulin pumps are able to deliver bolus insulin as a standard, extended or combination bolus.

There is minimal research to determine which bolus is preferable in different settings. Anecdotally, many patients utilizes only the standard bolus (SB) due to uncertainty regarding when and how to program the different bolus types. We compared postprandial glycemia when five different extended boluses (EBs) and an SB were used following a test meal. We sought to determine the impact of varying rates of insulin delivery from an EB on early postprandial glycemia.

Methods: We conducted a randomized, repeated measures trial of 20 children and adults comparing postprandial glycemic excursions following EBs given at five different rates with SB as a control. All EBs were delivered over $2 \mathrm{~h}$. Rates of EBs were chosen to reflect EBs used in clinical practice: $E B 1 H R=100 \%$ of insulin: carbohydrate ratio (ICR) per hour (200\% ICR total dose); EB2HR $=50 \%$ of ICR per hour; EB3HR=33\% of ICR per hour; EB4HR $=25 \%$ of ICR per hour; $\mathrm{EB} 6 \mathrm{HR}=16 \%$ ICR per hour. A standardized breakfast was given and activity was standardized. Continuous glucose monitoring was used to assess glycemia for $2 \mathrm{~h}$ after the meal.

Results: The mean postprandial glycemic excursions were lower at 30,60 , and $90 \mathrm{~min}(p<0.05)$ for SB compared with all EBs. The mean peak postprandial glycemic excursion and the area under the curve was lower for SB compared with all EBs $(p<0.05)$.

Discussion: EBs resulted in higher postprandial glycemic excursions than SB for $2 \mathrm{~h}$ after the meal. For a moderate glycemic index meal EBs are unable to control glycemia for $2 \mathrm{~h}$ after a meal as well as SB. Further studies with different meal types are required to determine the impact of differential delivery of the EB on postprandial glycemia.

Trial registration number: ACTRN12612000609853.

\section{INTRODUCTION}

Modern insulin pumps are capable of delivering meal bolus insulin in three main ways: standard bolus (SB) or rapid bolus, where the insulin is delivered immediately; extended or

\section{Key messages}

- Extended insulin boluses have been recommended for high fat and protein meals, low glycemic index meals, and in persons with gastroparesis with little research evidence to support such recommendations.

- In this study of children and adults with wellcontrolled type 1 diabetes without evidence of complications of diabetes, extended insulin boluses resulted in unacceptable early postprandial hyperglycemia that was not shown with a standard bolus.

- Further studies of extended boluses across meal types and in different patient groups should be performed to determine whether there is any clinical indication for their use.

square wave bolus, where the insulin delivery is spread over a longer time period; and combination or dual wave bolus, where a percentage of the insulin is delivered as a rapid bolus and the remainder is delivered as an extended bolus (EB). Minimal research has been performed to date comparing the different methods of meal bolus insulin delivery.

In our clinical practice, most patients and families exclusively use the SB to deliver the mealtime insulin dose. This is despite current recommendations to use extended and combination boluses for meals high in fat and protein, low glycemic index (GI) meals, and for persons with gastroparesis. ${ }^{1-5}$ Anecdotally, patients and families report confusion in utilizing the different bolus types due to uncertainty regarding the optimal rate of delivery. To the best of our knowledge, there is no current evidence-based guideline available to assist clinicians, patients and families wishing to program an extended or combination insulin bolus.

Studies of extended insulin boluses are particularly limited. Research to date has suggested that extended insulin boluses are not 
able to control the postprandial glucose rise for up to 120 min after a meal as well as a standard or combination bolus. ${ }^{6}{ }^{7}$ This finding limits the utility of ESs, as postprandial hyperglycemia has been associated with complications of diabetes. ${ }^{8-10}$ However, thus far, multiple rates of extended insulin bolus have not been compared in a clinical research setting. We sought to determine whether increasing the rate of the EB could prevent the postprandial hyperglycemia seen at 60 min following an EB in previous studies. ${ }^{67}$ Our aim was to determine the rate of insulin delivery required for an extended insulin bolus to control the early postprandial glucose rise. Our goal was to determine an evidence-based guideline for patients and families wishing to utilize the EB feature of their insulin pump.

\section{METHODS}

Participants

This study was a randomized, within-person, repeated measures trial conducted at the John Hunter Children's Hospital, Newcastle, Australia. Children and young adults with type 1 diabetes mellitus (T1DM) diagnosed for $\geq 1$ year and treated with insulin pump therapy for $\geq 6$ months were eligible for recruitment. Inclusion criteria were age between 7 and 39 years inclusive, glycated hemoglobin (HbAlc) $\leq 8 \%(64 \mathrm{mmol} / \mathrm{mol})$, and body mass index $\leq 97$ th centile. Exclusion criteria were coexisting medical problems (including celiac disease), use of medication affecting blood glucose levels (BGLs) other than insulin, complications of diabetes (eg, gastroparesis), inability or unwillingness to take the test meals and inability to take part in the study day due to premeal hyperglycemia (BGL $\geq 12 \mathrm{mmol} / \mathrm{L}$ ) or hypoglycemia (BGL $\leq 3.5 \mathrm{mmol} / \mathrm{L})$.

The study was completed in compliance with the Declaration of Helsinki and the International Conference on Harmonisation Good Clinical Practice Guidelines. Written informed consent and assent was obtained from all participants and their guardians if less than 18 years.

\section{Study procedure}

In the week prior to the study, participants and/or their guardians were contacted daily to review the patient's BGLs. Adjustments were made to the insulin pump settings as necessary to meet a prebreakfast BGL target of 4-8 $\mathrm{mmol} / \mathrm{L}$ and to optimize the breakfast insulin:carbohydrate ratio (ICR) to meet a prelunch BGL target of 4$8 \mathrm{mmol} / \mathrm{L}$. During the study period participants were instructed not to adjust their insulin pump settings.

A standardized, moderate GI meal was provided to each participant for consumption each day for 6 days at breakfast. The test meal consisted of a breakfast cereal, full cream milk, toast, and orange juice and contained $60 \mathrm{~g}$ of carbohydrate, $10 \mathrm{~g}$ of fat, and $10 \mathrm{~g}$ of protein. The meal was based on foods commonly consumed by people with diabetes in our clinic. Meals were individually packaged, with instructions to keep chilled prior to consumption. Food was prepared under controlled conditions and was weighed using Salter kitchen scales (accuracy \pm 1 g; model 323, Salter, Kent, UK). It is clinical practice in some Australian clinics to recommend the use of EBs for all meals (not just high fat or low GI) in an effort to optimize postprandial glycemia.

The insulin dose for each participant was determined for the meal using the participant's individualized ICR. Five different EB rates and one SB were delivered in random order at breakfast over the 6 days of the study.

The rates chosen for the EBs were based on how these boluses are delivered in clinical practice. In our clinic, the recommended insulin amount for an EB is equal to the ICR. Typically, EBs are delivered over 1-6 h. EB1HR delivered $100 \%$ of the ICR per hour for $2 \mathrm{~h}$ (total insulin dose $200 \%$ ICR) and represents the rate of insulin delivery for an EB given over $1 \mathrm{~h}$, EB2HR delivered $50 \%$ of the ICR per hour for $2 \mathrm{~h}$ (total insulin dose $100 \%$ ICR) and represents the rate of insulin delivery for an EB given over $2 \mathrm{~h}$, EB3HR delivered $33 \%$ of the ICR per hour for $2 \mathrm{~h}$ (total insulin dose $66 \%$ ICR) and represents an EB given over $3 \mathrm{~h}$, EB4HR delivered $25 \%$ of the ICR per hour for $2 \mathrm{~h}$ (total insulin dose $50 \%$ ICR) and represents an EB given over $4 \mathrm{~h}$ and EB6HR delivered $16 \%$ of the ICR per hour for $2 \mathrm{~h}$ (total insulin dose 32\% ICR) and represents an EB given over $6 \mathrm{~h}$. Participants were randomized according to computer generated randomization to deliver each bolus once. The EBs were given for $2 \mathrm{~h}$ and the glucose level was monitored for $2 \mathrm{~h}$ after the test meal with continuous glucose monitoring (CGM). The study period was for the $2 \mathrm{~h}$ postprandial period.

The observation period was increased to $3 \mathrm{~h}$ for the SB and the EB2HR, where the total insulin dose was identical, to allow interpretation of the glycemic curves until they returned to baseline.

Participants were required to fast overnight for at least $6 \mathrm{~h}$ prior to breakfast and for $2 \mathrm{~h}$ following the test meal. The bolus administration was started immediately prior to the participant eating the test breakfast. Administering the insulin bolus immediately before the meal is common practice in our clinic as it decreases the likelihood of it being forgotten or the child becoming distracted and not eating at the specified time. Participants were required to consume the test meal within $20 \mathrm{~min}$. If patients developed hypoglycemia (BGL $\leq 3.5 \mathrm{mmol} / \mathrm{L}$ or symptoms of hypoglycemia and BGL $\leq 4.0 \mathrm{mmol} / \mathrm{L}) 15 \mathrm{~g}$ of oral carbohydrate was given and analysis stopped at that point.

Participants changed their insulin pump site on days 1,3 , and 5 of the study.

A capillary blood glucose, food and activity diary was kept by each participant and their caregiver to assess adherence to the study protocol. Only sedentary activity was permitted during the $2 \mathrm{~h}$ postprandial period.

\section{Blood glucose measurement}

The iPro2 Continuous Glucose Monitoring System (Medtronic MiniMed, Northbridge, California, USA) 
was used to determine postprandial BGLs over the 6 days of the study. Participants and their guardians were blinded to the CGM analysis.

Participants attended the clinic on the afternoon prior to the start of the study for insertion of CGM. The instructions for use of the CGM, as per the manufacturer's guidelines, were discussed with the participant and/or their caregiver. Participants were asked to record at least four capillary blood glucose measurements per day into their study diary for calibration of the CGM.

At the completion of the study, data was downloaded from the CGM using the Medtronic CarelinkiPro data system (Medtronic MiniMed).

\section{Statistical analysis}

A sample size of 20 participants was calculated to provide $80 \%$ power to detect a difference of postprandial blood glucose excursions of $3 \mathrm{mmol} / \mathrm{L}$ at $60 \mathrm{~min}$ with a $5 \%$ significance level, assuming a within-person $\mathrm{SD}$ in BGL of $2 \mathrm{mmol} / \mathrm{L}$.

The primary outcome measure was the postprandial glucose excursion at $60 \mathrm{~min}$. This measure was chosen as we sought to determine whether increasing the rate of the EB could prevent the postprandial hyperglycemia seen at $60 \mathrm{~min}$ following an EB in previous studies. ${ }^{6} 7$ Secondary outcomes included the postprandial glucose excursions at $30 \mathrm{~min}$ intervals from 30 to $120 \mathrm{~min}$, the peak postprandial glucose excursion, the time to peak postprandial glucose excursion, and hypoglycemic events defined as capillary BGL $\leq 3.5 \mathrm{mmol} / \mathrm{L}$ or capillary BGL $\leq 4.0 \mathrm{mmol} / \mathrm{L}$ with symptoms of hypoglycemia.

Data was analyzed in STATA V.11. A mixed models logistic analysis was used to compare postprandial glycemic excursions. McNemar's test was used to examine differences in hypoglycemic events. Regression analysis was used to compare area under the curve.

\section{RESULTS}

Twenty participants (10 male) aged 7-36 years were included with a mean age of $18 \pm 2.4$ years. Mean $\mathrm{HbAlc}$ was $7.0 \pm 0.2 \%(53 \mathrm{mmol} / \mathrm{mol})$. Mean duration of diagnosis of T1DM was $7.4 \pm 1.5$ years and duration of insulin pump therapy was $3.9 \pm 0.6$ years. The mean insulin bolus dose at breakfast was 1 unit/8.6 $\pm 0.2 \mathrm{~g}$ of carbohydrate.

\section{Preprandial BGLS}

There was no difference in the preprandial BGLs between the different bolus types $(\mathrm{p}<0.05$; see table 1$)$.

\section{Postprandial glycemic excursion}

Figure 1 illustrates the mean postprandial glycemic excursion for $120 \mathrm{~min}$ following the meal for each of the bolus types. At $60 \mathrm{~min}$ following the test meal, the glycemic excursion was significantly lower following the $\mathrm{SB}$ than all EBs (SB $2.9 \pm 2.8 \mathrm{mmol} / \mathrm{L}$ vs EB1HR $(4.9 \pm 3.1 \mathrm{mmol} / \mathrm{L}$, $\mathrm{p}<0.02)$, EB2HR $(4.7 \pm 4.2 \mathrm{mmol} / \mathrm{L}, \mathrm{p}<0.05)$, EB3HR (5.8 $\pm 4.4 \mathrm{mmol} / \mathrm{L}, \mathrm{p}<0.01), \mathrm{EB} 4 \mathrm{HR}(6.2 \pm 4.0 \mathrm{mmol} / \mathrm{L}, \mathrm{p}<0.01)$, and EB6HR $(6.4 \pm 3.4 \mathrm{mmol} / \mathrm{L}, \mathrm{p}<0.01))$. At $90 \mathrm{~min}$ following the test meal, the glycemic excursion remained significantly lower following the SB than all EBs (SB 2.4 \pm 0.9 $\mathrm{mmol} / \mathrm{L}$ vs EB1HR $(5.4 \pm 0.9 \mathrm{mmol} / \mathrm{L}, \mathrm{p}<0.02)$, EB2HR $(4.8 \pm 1.0 \mathrm{mmol} / \mathrm{L}, \quad \mathrm{p}<0.04), \quad$ EB3HR $\quad(6.6 \pm 1.1 \mathrm{mmol} / \mathrm{L}$, $\mathrm{p}<0.01)$, EB4HR $(7.6 \pm 1.0 \mathrm{mmol} / \mathrm{L}, \mathrm{p}<0.01)$, and EB6HR $(7.2 \pm 1.0 \mathrm{mmol} / \mathrm{L}, \mathrm{p}<0.01))$. At $120 \mathrm{~min}$ following the test meal, the mean glycemic excursion remained lower following the SB than all EBs, however a statistically significant difference was found only for EB3HR, EB4HR, and EB6HR (SB 1.76 $\pm 4.4 \mathrm{mmol} / \mathrm{L}$ vs EB1HR $(3.6 \pm 4.0 \mathrm{mmol} / \mathrm{L}$, $\mathrm{p}=0.09)$, EB2HR $(3.1 \pm 4.3 \mathrm{mmol} / \mathrm{L}, \mathrm{p}=0.18)$, EB3HR (5.4 $\pm 3.9 \mathrm{mmol} / \mathrm{L}, \mathrm{p}<0.01), \mathrm{EB} 4 \mathrm{HR}(6.6 \pm 4.0 \mathrm{mmol} / \mathrm{L}, \mathrm{p}<0.01)$, and EB6HR (7.2 $\pm 4.2 \mathrm{mmol} / \mathrm{L}, \mathrm{p}<0.01$; see table 2$))$.

\section{Peak glycemic excursion}

The peak glycemic excursion was lower for SB (4.1 \pm 3.5 $\mathrm{mmol} / \mathrm{L})$ compared with EB1HR $(6.6 \pm 3.2 \mathrm{mmol} / \mathrm{L}$, $\mathrm{p}<0.02)$, EB2HR $(5.9 \pm 3.5 \mathrm{mmol} / \mathrm{L}, \mathrm{p}=0.06)$, EB3HR $(7.3$ $\pm 5.2 \mathrm{mmol} / \mathrm{L}, \mathrm{p}<0.01), \mathrm{EB} 4 \mathrm{HR}(8.4 \pm 4.0 \mathrm{mmol} / \mathrm{L}, \mathrm{p}<0.01)$, and EB6HR $(8.1 \pm 3.6 \mathrm{mmol} / \mathrm{L}, \mathrm{p}<0.01$; see table 2$)$.

\section{Time to peak glycemic excursion}

The time to peak glycemic excursion was less for an $\mathrm{SB}$ $(60.0 \pm 35.1 \mathrm{~min})$ compared with EB1HR $(75.3 \pm 18.2 \mathrm{~min}$, $\mathrm{p}<0.05)$, EB2HR (71.1 $\pm 45.2 \mathrm{~min}, \mathrm{p}=0.20)$, EB3HR (94.2 $\pm 47.0 \mathrm{~min}, \mathrm{p}<0.01), \quad$ EB4HR $(85.0 \pm 20.9 \mathrm{~min}, \mathrm{p}<0.01)$, and EB6HR (95.3 $\pm 35.4 \mathrm{~min}, \mathrm{p}<0.01$; see table 2$)$.

Table 1 Mean preprandial BGL, mean PPGE at 1 and $2 \mathrm{~h}$, peak PPGE, time to peak PPGE and mean $2 \mathrm{~h}$ AUC following an $\mathrm{SB}$ and five different insulin infusion rates for an EB given for a test meal

\begin{tabular}{lllllll}
\hline & $\begin{array}{l}\text { Preprandial } \\
\text { BGL (mmol/L) }\end{array}$ & $\begin{array}{l}\text { Mean 1 h PPGE } \\
(\mathbf{m m o l} / \mathbf{L})\end{array}$ & $\begin{array}{l}\text { Mean 2 h } \\
\text { PPGE }(\mathbf{m m o l} / \mathbf{L})\end{array}$ & $\begin{array}{l}\text { Peak PPGE } \\
(\mathbf{m m o l} / \mathbf{L})\end{array}$ & $\begin{array}{l}\text { Time to peak } \\
\text { PPGE (mins) }\end{array}$ & $\begin{array}{l}\text { Mean 2 h AUC } \\
(\mathbf{m m o l} / \mathbf{h} / \mathbf{L})\end{array}$ \\
\hline SB & $8.5 \pm 3.3$ & $2.9 \pm 2.7$ & $1.8 \pm 1.0$ & $4.1 \pm 3.5$ & $60 \pm 35.1$ & $249.1 \pm 68.7$ \\
EB1HR & $7.6 \pm 2.5$ & $4.9 \pm 3.1^{*}$ & $3.6 \pm 0.9$ & $6.6 \pm 3.2^{*}$ & $75.3 \pm 18.2^{*}$ & $443.9 \pm 90.1^{*}$ \\
EB2HR & $8.8 \pm 3.0$ & $4.7 \pm 4.2^{*}$ & $3.1 \pm 1.0$ & $5.9 \pm 3.5$ & $71.1 \pm 45.2$ & $440.3 \pm 91.6^{*}$ \\
EB3HR & $8.7 \pm 3.0$ & $5.8 \pm 4.4^{*}$ & $5.4 \pm 0.9^{*}$ & $7.3 \pm 5.2^{*}$ & $94.2 \pm 47.0^{*}$ & $564.8 \pm 90.1^{*}$ \\
EB4HR & $7.9 \pm 3.4$ & $6.2 \pm 4.0^{*}$ & $6.6 \pm 0.9^{*}$ & $8.4 \pm 4.0^{*}$ & $85.0 \pm 20.9^{*}$ & $593.5 \pm 91.6^{*}$ \\
EB6HR & $9.0 \pm 3.8$ & $6.4 \pm 3.4^{*}$ & $7.2 \pm 1.0^{*}$ & $8.1 \pm 3.6^{*}$ & $95.3 \pm 35.4^{*}$ & $596.2 \pm 91.6^{*}$ \\
\hline
\end{tabular}

${ }^{*} \mathrm{p}<0.05$.

AUC, area under the curve; BGL, blood glucose levels; EB, extended bolus; PPGE, postprandial glycemic excursion; SB, standard bolus. 




Figure 1 Postprandial glycemic excursions for $120 \mathrm{~min}$ following a standard bolus and five different insulin infusion rates for an extended bolus (EB) given for a standardized test meal.

\section{Area under the curve}

The area under the curve was significantly less for SB $(249.1 \pm 68.7 \mathrm{mmol} / \mathrm{h} / \mathrm{L})$ compared with EB1HR (443.9 $\pm 90.1 \mathrm{mmol} / \mathrm{h} / \mathrm{L}, \mathrm{p}<0.04)$, EB2HR $(440.3 \pm 91.6 \mathrm{mmol} /$ $\mathrm{h} / \mathrm{L}, \mathrm{p}<0.04)$, EB3HR $(564.8 \pm 90.1 \mathrm{mmol} / \mathrm{h} / \mathrm{L}, \mathrm{p}<0.01)$, EB4HR (593.5 $\pm 91.6 \mathrm{mmol} / \mathrm{h} / \mathrm{L}, \mathrm{p}<0.01)$, and $\mathrm{EB} 6 \mathrm{HR}$ $(596.2 \pm 91.6 \mathrm{mmol} / \mathrm{h} / \mathrm{L}, \mathrm{p}<0.01$; see table 2$)$.

\section{Hypoglycemic events}

There was one hypoglycemic event in the SB group and one in the EB1HR bolus group.

\section{SB versus EB2HR}

Figure 2 illustrates the mean postprandial glycemia excursion for SB and EB2HR for 180 min following the test meal. The postprandial glycemic excursion following the test meal was significantly lower for SB compared with EB2HR from 15 to $60 \mathrm{~min}$ and at $90 \mathrm{~min}$ following the test meal. By $180 \mathrm{~min}$ after the test meal, the glycemic excursion was significantly higher for SB compared with EB2HR (see table 3).

\section{DISCUSSION}

We found that for a standardized moderate GI test meal of mixed macronutrient composition, an extended



Figure 2 Postprandial glycemic excursions for $180 \mathrm{~min}$ following a standard bolus and an extended bolus (EB2HR) of identical total insulin dose given for a standardized test meal.

insulin bolus was unable to control the early postprandial glucose rise as well as an SB. In particular, we found that even when the total insulin dose was double the ICR, as demonstrated by EB1HR, the extended insulin bolus was still unable to control postprandial glycemia over a $2 \mathrm{~h}$ period as well as an SB. Furthermore, there was no increase in the rate of hypoglycemia with SB compared with EB.

This is the first study known to the authors to compare early postprandial glycemia following a standardized meal for EBs given at five different rates, as well as an SB. We aimed to determine whether increasing the rate of delivery of the EB could prevent postprandial hyperglycemia for up to $120 \mathrm{~min}$ shown in previous studies using an EB. ${ }^{6}{ }^{7}$ We only studied the $2 \mathrm{~h}$ postprandial period, however, we hypothesize the loss of blood glucose control in the initial postprandial period with the extended insulin bolus negates any possible finding of improved control in the later postprandial period. Studies extending the period of observation after the test meal would have defined a period of hyperglycemia for the different EBs.

We used a standardized test meal that reflected a common breakfast meal eaten by Australian children and adults. This allowed us to study the postprandial

Table 2 Postprandial glycemic excursions from 15 to 120 min following an SB and five different insulin infusion rates for an EB given for a test meal

\begin{tabular}{|c|c|c|c|c|c|c|c|c|}
\hline \multicolumn{9}{|c|}{ Postprandial glycemic excursion (mmol/L) } \\
\hline & $15 \mathrm{~min}$ & $30 \mathrm{~min}$ & $45 \mathrm{~min}$ & $60 \mathrm{~min}$ & $75 \mathrm{~min}$ & $90 \mathrm{~min}$ & $105 \mathrm{~min}$ & $120 \mathrm{~min}$ \\
\hline SB & $0.2 \pm 0.1$ & 0.80 .3 & $1.8 \pm 0.5$ & $2.9 \pm 2.7$ & $2.7 \pm 0.7$ & $2.4 \pm 0.9$ & $2.1 \pm 1.0$ & $1.8 \pm 1.0$ \\
\hline EB1HR & $0.3 \pm 0.1$ & $1.8 \pm 0.3^{*}$ & $3.7 \pm 0.5^{\star}$ & $4.9 \pm 3.1^{*}$ & $5.6 \pm 0.9^{*}$ & $5.4 \pm 0.9^{*}$ & $4.8 \pm 1.0^{*}$ & $3.6 \pm 0.9$ \\
\hline EB2HR & $0.7 \pm 0.2^{*}$ & $2.3 \pm 0.5^{*}$ & $3.9 \pm 0.8^{*}$ & $4.7 \pm 4.2^{*}$ & $4.8 \pm 1.1$ & $4.8 \pm 1.0^{*}$ & $4.4 \pm 1.0$ & $3.1 \pm 1.0$ \\
\hline EB3HR & $0.7 \pm 0.2^{*}$ & $2.3 \pm 0.6^{*}$ & $4.2 \pm 1.8^{\star}$ & $5.8 \pm 4.4^{*}$ & $6.5 \pm 1.1^{*}$ & $6.6 \pm 1.1^{*}$ & $6.4 \pm 1.0^{*}$ & $5.4 \pm 0.9^{*}$ \\
\hline EB4HR & $0.7 \pm 0.3$ & $2.5 \pm 0.6^{*}$ & $4.7 \pm 0.8^{*}$ & $6.2 \pm 4.0^{*}$ & $6.9 \pm 1.0^{*}$ & $7.6 \pm 1.0^{*}$ & $7.5 \pm 1.0^{*}$ & $6.6 \pm 0.9^{*}$ \\
\hline EB6HR & $0.8 \pm 0.2^{*}$ & $2.7 \pm 0.4^{*}$ & $4.9 \pm 0.6^{\star}$ & $6.4 \pm 3.4^{*}$ & $6.9 \pm 0.9^{*}$ & $7.2 \pm 1.0^{*}$ & $7.3 \pm 1.0^{*}$ & $7.2 \pm 1.0^{*}$ \\
\hline
\end{tabular}

${ }^{*} \mathrm{p}<0.05$.

EB, extended bolus; SB, standard bolus. 
Table 3 Mean preprandial BGL, mean postprandial glycemic excursion at 60,120 , and 180 min, peak postprandial glycemic excursion, time to peak postprandial glycemic excursion and mean 120 min AUC following an SB and an EB of equal total insulin dose delivered over $120 \mathrm{~min}$

\begin{tabular}{lrr}
\hline & SB & EB2HR \\
\hline Preprandial BGL (mmol/L) & $8.5 \pm 3.3$ & $8.8 \pm 3.0$ \\
Mean 60 min postprandial glycemic excursion (mmol/L) & $2.9 \pm 2.7$ & $4.7 \pm 4.2^{*}$ \\
Mean 120 min postprandial glycemic excursion (mmol/L) & $1.8 \pm 1.0$ & $3.1 \pm 1.0$ \\
Mean 180 min postprandial glycemic excursion (mmol/L) & $-0.4 \pm 4.5$ & $-3.3 \pm 3.6^{*}$ \\
Peak postprandial glycemic excursion (mmol/L) & $4.1 \pm 3.5$ & $5.9 \pm 3.5$ \\
Time to peak postprandial glycemic excursion (mins) & $60 \pm 35.1$ & $71.1 \pm 45.2$ \\
Mean 120 min AUC (mmol/h/L) & $249.1 \pm 68.7$ & $440.3 \pm 91.6^{*}$ \\
\hline
\end{tabular}

${ }^{*} \mathrm{p}<0.05$.

AUC, area under the curve; BGL, blood glucose levels; EB, extended bolus; SB, standard bolus.

glucose control achieved with an EB and SB following a typical meal, in order to provide advice to patients and families wishing to utilize the EB. We considered the test meal to be a moderate-GI, moderate-fat, moderateprotein meal. As the extended insulin bolus has been suggested for low GI meals and high-fat, high-protein meals, as well as for persons with gastroparesis, our study may have been bolstered if different meal types were used. ${ }^{1-5}$ Nonetheless, all meal types, including high-fat and low-GI meals, result in an initial postprandial glucose rise. Smart $e t a l^{11}$ found that the glycemic excursion following a high-fat meal was $2.2 \mathrm{mmol} / \mathrm{L}$ at 60 min. Ryan et al ${ }^{12}$ showed a peak glycemic excursion of $4.6 \mathrm{mmol} / \mathrm{L}$ for a low-GI meal. Future studies could be conducted using an extended insulin bolus for a variety of meal types.

There are only two studies known to the authors, which utilize the EB feature of insulin pumps. Chase et at found that for a pizza meal, an extended insulin bolus delivered over $2 \mathrm{~h}$ was not able to control postprandial glycemia as well as SB for up to $120 \mathrm{~min}$ following the test meal. However, postprandial control at $4 \mathrm{~h}$ after the meal was improved compared with an SB. Our study, while only including 20 participants, is larger than this study of 9 participants. We also compared multiple rates of EB delivery with an SB, rather than a single rate. However, the period of observation of the Chase et at study was $6 \mathrm{~h}$, providing valuable insight into postprandial glucose levels for many hours after the test meal. Both studies suggest that the extended insulin bolus is ineffective in controlling early postprandial hyperglycemia.

Lindholm-Olinder et al compared an SB, EB and combination bolus given for two meals with different fat, carbohydrate and protein contents in 14 adolescent girls with T1DM. At 60 min following the higher fat meal, the BGL was significantly higher for the ED compared with SB and combination bolus. ${ }^{10}$ This study adds weight to our finding that an extended insulin bolus is unable to control hyperglycemia in the early postprandial period.

Our study demonstrated that for a standardized meal, the extended insulin bolus is not able to control the early postprandial glucose rise as well as an SB, irrespective of the rate of insulin delivery. This finding suggests that the EB may only be a useful tool in certain clinical scenarios, such as in a person with gastroparesis. We suggest that further studies of the EB in such situations, as well as across meal types, are required to determine whether recommendations for using the EB should be amended.

Circadian variations in cortisol, growth hormone and other hormones may increase insulin requirements in the morning hours. ${ }^{13}$ We chose breakfast for our study as we have successfully utilized this methodology in other studies as it permits meal and activity supervision. ${ }^{11} 12$

The timing of the mealtime insulin bolus may impact postprandial glycemia. Studies suggest that giving the insulin bolus up to $30 \mathrm{~min}$ before a meal may be beneficial. ${ }^{13}{ }^{14}$ In everyday life most persons living with T1DM deliver mealtime insulin boluses immediately prior to eating, hence for this study we chose to deliver the EB just prior to the test meal. However, the EB may be able to better control the postprandial glucose rise if delivered 20-30 min before a meal, and thus may be beneficial for certain meal types that result in prolonged glucose absorption.

Only a single meal type was used in this study. Altering the amount or type of carbohydrate may have impacted postprandial glycemic control in the study participants. Furthermore, fat and protein have been shown to impact postprandial BGLs. ${ }^{13}{ }^{15}$ Smart et al found a higher rate of hypoglycemia after a low-fat meal. ${ }^{13}$ In this situation, there may be some benefit for an EB in preventing early postprandial hypoglycemia. Adjusting the fat and protein content of the study meal may have also impacted the postprandial glucose levels in the study.

The participants in this study had well-controlled T1DM and did not have any known complications of the disease. Extended insulin boluses have been recommended for persons with gastroparesis. ${ }^{2}$ Future studies including persons with known gastroparesis, or persons with higher HbAlc and therefore increased likelihood of complications of diabetes, may be useful to determine the utility of the EB in these patient groups. 
In this study, we demonstrated that an extended insulin bolus was inferior to SB in controlling postprandial glycemia following a standard breakfast meal. Future studies comparing the EB and SB across a range of meal types and times may be performed to determine the utility of EB in clinical practice.

Acknowledgements The authors thank the John Hunter Children's Hospital Paediatric Diabetes Team for assistance with carrying out the study. They also thank Professor Roger Smith of the Hunter Medical Research Institute, Mothers and Babies Research Group, Newcastle, Australia for advice and support. And particularly would like to thank all the study participants and their families.

Contributors PL, CS, and BK designed the study. PL, BK, CS, and CM recruited the patients. PL and MP conducted the study and collected the data. PM analyzed the data. PL wrote the first draft of the manuscript, which was edited by CS and BK. BK is the guarantor.

Funding This study was supported by a 2012 NovoNordisk Regional Support Scheme grant.

Competing interests PL receives PhD funding support by a 2011 NovoNordisk grant.

Patient consent Obtained.

Ethics approval University of Newcastle and Hunter New England Human Research Ethics Committee.

Provenance and peer review Not commissioned; externally peer reviewed.

Data sharing statement No additional data are available.

Open Access This is an Open Access article distributed in accordance with the Creative Commons Attribution Non Commercial (CC BY-NC 4.0) license, which permits others to distribute, remix, adapt, build upon this work noncommercially, and license their derivative works on different terms, provided the original work is properly cited and the use is non-commercial. See: http:// creativecommons.org/licenses/by-nc/4.0/

\section{REFERENCES}

1. Smart C, Aslander Van Vliet E, Waldron S. ISPAD clinical practice consensus guidelines 2009 compendium. Nutritional management in children and adolescents with diabetes. Pediatr Diabetes 2009;10 (Suppl 12):18.

2. Wolpert H. Smart pumping for people with diabetes. Alexandria: American Diabetes Association, 2002.

3. Darnell C. The extended bolus: the secret to mealtime insulin. Roche Diagnostics. 2012 [updated 19 August 2013; cited 201320 August 2013].

4. Medtronic Diabetes, ed. Dual/Square Wave quick reference guide for the Paradigm Revel Insulin Pump. 2013.

5. Animas Vibe Insulin Pump and CGM System. 2013 [updated 8 April 2013; cited 20 August 2013].

6. Chase H, Saib S, MacKenzie T, et al. Post-prandial glucose excursions following four methods of bolus insulin administration in subjects with type 1 diabetes. Diabet Med 2002;19:317-21.

7. Lindholm Olinder A, Runefors J, Smide B, et al. Post-prandial glucose levels following three methods of insulin bolusing. A study in adolescent girls and in comparison with girls without diabetes. Pract Diab Int 2009;26:110-15.

8. Mah E, Bruno R. Postprandial hyperglycemia on vascular endothelial function: mechanisms and consequences. Nutr Res 2012;32:727-40.

9. Ceriello $A$. The emerging role of postprandial hyperglycaemic spikes in the pathogenesis of diabetic complications. Diabet Med 1998;15:188-93.

10. Einarson T, Hunchuck J, Hemels M. Relationship between blood glucose and carotid intima media thickness: A meta-analysis. Cardiovasc Diabetol 2010;13:37-44.

11. Smart C, Evans M, O'Connell S, et al. Both dietary protein and fat increase postprandial glucose excursions in children with type 1 diabetes, and the effect is additive. Diabetes Care 2013;36: 3897-902.

12. Ryan R, King B, Anderson D, et al. Influence of and optimal insulin therapy for a low-glycaemic index meal in children with type 1 diabetes receiving intensive insulin therapy. Diabetes Care 2008;31:6.

13. Trumper BG, Reschke K, Molling J. Circadian variation of insulin requirement in insulin dependent diabetes mellitus the relationship between circadian change in insulin demand and diurnal patterns of growth hormone, cortisol and glucagon during euglycemia. Horm Metab Res 1995;27:141-7.

14. Scaramuzza $A$, lafusco $D$, Santoro $L$, et al. Timing of bolus in children with type 1 diabetes using continuous subcutaneous insulin infusion (TiBoDi study). Diabetes Technol Ther 2010;12:149-52.

15. Wolpert $\mathrm{H}$, Atakov-Castillo A, Smith $\mathrm{S}$, et al. Dietary fat acutely increases glucose concentrations and insulin requirements in patients with Type 1 Diabetes: implications for carbohydrate-based bolus dose calculation and intensive diabetes management. Diabetes Care 2013;36:810-16. 